\title{
Correlation between nurses' attitudes towards death and their subjective well-being
}

\author{
Jiali Zhang ${ }^{1,2}$, Hongmei Tao ${ }^{2}$, Jundan $^{\text {Mao }}{ }^{3}$, Xue Qi ${ }^{3}$, Hongzhen Zhou ${ }^{4}$ \\ ${ }^{1}$ School of Nursing, Southern Medical University, Guangzhou, China; ${ }^{2}$ Department of Medicine, the Fifth Affiliated Hospital of Sun Yat-sen \\ University, Zhuhai, China; ${ }^{3}$ Department of Geriatrics, the Fifth Affiliated Hospital of Sun Yat-sen University, Zhuhai, China; ${ }^{4}$ Department of \\ Nursing, Nanfang Hospital, Southern Medical University, Guangzhou, China \\ Contributions: (I) Conception and design: H Zhou; (II) Administrative support: H Zhou; (III) Provision of study materials or patients: J Zhang, H Tao \\ (IV) Collection and assembly of data: H Tao, J Mao; (V) Data analysis and interpretation: J Zhang, X Qi; (VI) Manuscript writing: All authors; (VII) \\ Final approval of manuscript: All authors. \\ Correspondence to: Hongzhen Zhou. Department of Nursing, Nanfang Hospital, Southern Medical University, Baiyun District, Guangzhou 518000, \\ China. Email: zhouhz2005@126.com.
}

\begin{abstract}
Background: With China's ageing society, the number of deaths increased gradually. Clinical nursing staff are among the first to come into contact with dying patients and scientific attitudes towards death will affect not only the quality of hospice care but also the physical and mental health of the nursing staff. Subjective well-being (SWB) mainly points to the overall emotional and cognitive evaluation of life quality. However, few studies have examined the correlation between attitudes towards death and subjective well-being in nurses.
\end{abstract}

Methods: A total of 810 nurses recruited from a tertiary hospital in Zhuhai were surveyed using the Chinese version of the Death Attitude Profile-Revised and the Subjective Well-being Scale. Pearson correlation coefficient was computed to analyze the correlation between attitudes towards death and the subjective well-being of the nursing staff.

Results: Subjective well-being was correlated with attitudes towards death $(\mathrm{P}<0.05)$. Multivariate analysis found that serious illness/acute or chronic disease, night shifts, and initial education level among nurses were also factors significantly related to subjective well-being $(\mathrm{P}<0.05)$.

Conclusions: The findings indicate a close correlation between nurses' attitudes towards death and their subjective well-being. Nursing managers should guide nursing staff to develop a more appropriate and healthier view of death so as to enhance their subjective well-being.

Keywords: Attitudes towards death; nurses; subjective well-being

Submitted Sep 18, 2021. Accepted for publication Nov 09, 2021.

doi: 10.21037/apm-21-2943

View this article at: https://dx.doi.org/10.21037/apm-21-2943

\section{Introduction}

In China, the aging population has continued to grow rapidly in recent years, and it is expected to reach 400 million by 2050, at which time there will be an estimated 94.48 million elderly people, accounting for $21.78 \%$ of the total population (1). Chinese people view the birth of a child as a joyful event, whereas death is regarded as taboo. With China's ageing society, there is an increasing need for high-quality care. When caring for patients who are close to the end of their life, medical personnel not only seek to alleviate the patient's physical pain but they also help their patients to adapt to their physical and psychological state

^ ORCID: 0000-0002-4746-9215. 
prior to their death, by engaging in effective measures and helping their patients, as much as possible, to reach the end of their life journey with dignity. Clinical nursing staff are among the first to come into contact with dying patients, and they may perform critical emergency interventions at any time. Poor scientific attitudes towards death will affect both the quality of hospice care and the physical and mental health of the nursing staff, eliciting negative emotions and adverse psychological reactions. Subjective well-being can be understood as an individual's overall emotional and cognitive evaluation of their quality of life (2). Wang et al. demonstrated that the care of dying patients was closely related with nurses' personal attitudes and the educational programmes of clinical nurses (3). Few studies have examined the correlation between attitudes towards death and subjective well-being, and there is a lack of research regarding this issue among nursing staff. Subjective wellbeing is a subjective and holistic concept that consists of emotional balance and life satisfaction. Humans are constantly evaluating and cognitively processing life events, living environment and happenings, which determines the happiness index. Subjective well-being was correlated with attitudes towards death, especially the nurses. The aim of the present study was to investigate prevailing attitudes towards death among nursing staff and to identify the influencing factors. We analyzed the correlation between attitudes towards death and subjective well-being to provide a scientific basis for the provision of essential training courses on death-related issues by medical colleges and units. The present study highlights the need for nursing managers to pay greater attention to the psychological state of clinical nursing staff, and to develop timely interventions to improve the subjective well-being of nursing staff. We present the following article in accordance with the SURGE reporting checklist (available at https://dx.doi. org/10.21037/apm-21-2943).

\section{Methods}

\section{Participants}

From August to October 2019, a convenient sampling method was used to select the clinical nursing staff participants from a tertiary hospital in Zhuhai, China. The inclusion criteria were as follows: (I) nursing staff with a Chinese nurse practitioner certificate; (II) those in clinical jobs, but not in administration departments, logistics departments, and supply rooms; and (III) those who agreed to voluntarily participate in the survey. The exclusion criteria were as follows: (I) advanced students or interns; and (II) those on sick leave or maternity leave during the investigation. Among the 810 clinical nurses who took part in the survey, 789 were female and 21 were male, and all participants were aged 20-59 years. A total of 785 participants were of Han ethnicity. A total of 385 participants were unmarried, 407 were married, and 10 were divorced or widowed. A total of 388 participants had children. Thirty-seven participants held religious beliefs. Seventeen participants had completed secondary schools, 191 participants completed junior college, and 602 held a bachelor degree or higher. A total of 321 participants held the professional title of nurse, 294 were senior nurses, and 195 were supervisor nurses or higher. In terms of working years, 122 participants had a tenure of 3 years or less, 168 participants had a tenure of $3-5$ years, and 310 participants had a tenure of more than 5 years. For geographical location, 427 nurses resided in rural areas, and 383 nurses resided in cities. A total of 181 participants had undertaken an educational course in death-related issues, 290 participants reported that they had relatives who currently suffered from a serious illness (including acute and chronic diseases), 102 participants reported that they had at some stage suffered from serious illness (including acute and chronic diseases), and 556 reported that they had provided hospice treatment for their relatives or patients. Real data is the most basic premise of the questionnaire and ensures the accuracy in analysis of questionnaire.

\section{Survey instruments}

\section{General information questionnaire}

The General Information Questionnaire covered the following information: sex, age, nationality, religious belief, marital status, whether or not the participant was an only child, whether the participant had children, monthly income, initial education level, highest education level, residence since childhood, current location of household registration, work department, total working years, number of years working in their current department, whether the participant had rotated departments, professional title, duties, number of night shifts, labor forms, whether the participant was a teacher within the department, whether the participant had received training in death-related issues, whether the participant had ever suffered from serious illness (including acute and chronic 
diseases), whether the participant had relatives who suffered from a serious illness (including acute and chronic diseases), whether the participant had witnessed serious accidents or life-threatening incidents, and whether the participant had provided hospice treatment for their patients or relatives.

\section{The Chinese version of the Death Attitude Profile- Revised}

The Death Attitude Profile-Revised was compiled by Wong et al. (4) in 1994, and was translated into Chinese by Liao with some cultural adjustments. These adjustments were carried out by Tang et al. (5), based on the crossculture principle to produce the Chinese version of the Death Attitude Profile-Revised, which took into account the cultural background of nurses in Mainland China. This profile consists of 32 entries, which includes 5 dimensions. Each entry was scored according to a 5-point Likert-type scale, ranging from 'disagree' to 'strongly agree'. The Cronbach's alpha reliability coefficient of the total profile was 0.875 , indicating good reliability. The rate of the total explained variation was $57.5 \%$, indicating good construct validity. The higher the score of each dimension, the greater the likelihood that the relevant dimension reflected nurses' attitudes towards death.

\section{Subjective Well-being Scale}

This scale was compiled by Fazio (6) in 1977 and contains 33 items (https://cdn.amegroups.cn/static/public/APM21-2943-1.pdf). The Chinese scholar, Duan, examined the first 18 items of the scale and found that the concordance coefficient of the scale was 0.91 in the male group and 0.95 in the female group, while the test-retest concordance coefficient was 0.85 , indicating good reliability. Furthermore, it is believed that the first 18 items are more suitable for the Chinese cultural background. Therefore, in the present study, the survey referred to the first 18 items of the scale, which included the following 6 factors: satisfaction with and interest in life, concern about health, energy levels, melancholic or pleasant mood, control over emotions and behavior, and relaxation and nervousness. The higher the total score (i.e., the subjective well-being score), the greater the level of subjective well-being.

The Chinese version of the Death Attitude ProfileRevised and the Subjective Well-being Scale to evaluate attitudes towards death and the current state of subjective well-being among clinical nurse practitioners are freely available for research use.

\section{Data collection}

Five senior nursing staff were selected from the departments to serve as investigators. These staff members were responsible for communicating all relevant information about the survey to the head nurses of all wards, as well as for obtaining the written informed consent of the participants prior to the commencement of the survey. At the monthly nursing staff meeting involving different departments, the investigators used appropriate language to provide a necessary, albeit simple, explanation to the nursing staff, with the aim of obtaining the support and cooperation of the nursing staff, as well as ensuring that they understood the purpose of the survey and what was required of them in terms of answering each item of the scales. The questionnaires were distributed and immediately retrieved onsite. The head nurses were entrusted to collect the questionnaires of nursing staff members who returned to their duties during the survey. A total of 830 questionnaires were distributed and all were returned. A total of 20 invalid questionnaires were eliminated, and the effective recovery rate of questionnaires was $97.8 \%$.

\section{Statistical analysis}

SPSS version 20.0 software (SPSS Inc., Chicago, USA) was used for the statistical analysis. After performing a normal distribution test to screen the data, the data measurement results were described as mean \pm standard deviation. An independent samples $t$-test or a single factor analysis of variance was used to carry out group comparisons. Enumeration data were expressed as frequencies and percentages. Differences in the variables among all groups were analyzed using Fisher's exact test. Pearson correlation coefficient was computed to analyze the correlation between attitudes towards death and the subjective well-being of the nursing staff. Potential confounding variables were adjusted by carrying out multiple linear regression analysis. A significance level of $0.05(\alpha=0.05)$ was selected, and $P<0.05$ indicated a statistically significant difference.

\section{Ethical considerations}

The study was conducted with the approval of the Medical Ethics Committee of the Fifth Affiliated Hospital of Sun Yat-sen University (approval No. K221-1). All participants provided written informed consent following an explanation of the procedures involved. They were 
instructed that participation was voluntary and anonymous, and that they could skip any questions they did not feel comfortable answering or withdraw from the study at any time. The study was carried out in accordance with the ethical guidelines of the Declaration of Helsinki (as revised in 2013).

\section{Results}

\section{Death attitude scale scores of nursing staff}

The average entry scores for the 5 dimensions of the Chinese version of Death Attitude Profile-Revised, ranked from highest to lowest, were as follows: $3.75 \pm 0.31$ points for natural acceptance, $2.99 \pm 0.76$ points for avoidance of death-related issues, $2.87 \pm 0.68$ points for fear of death, $2.68 \pm 0.65$ points for tendency towards acceptance, and $2.62 \pm 0.82$ points for escape from acceptance.

\section{Subjective well-being scores of nursing staff}

The total subjective well-being score was $70.91 \pm 9.43$. The score for satisfaction with and interest in life was $4.10 \pm 0.72$ points, $5.25 \pm 2.39$ points for concern about health, $16.92 \pm 4.08$ points for energy levels, $18.59 \pm 3.82$ points for melancholic or pleasant mood, $10.24 \pm 2.57$ points for control over emotions and behavior, and $15.22 \pm 3.59$ points for relaxation and nervousness.

\section{Single-factor analysis of attitudes towards death among nurses}

The results revealed statistically significant differences for different dimensions of the death attitude scale when the following factors were compared: nurses' duties, professional titles, residence since childhood, marital status, whether the participants had children, labor form, working years, whether the participants had rotated departments, whether the participants were teachers within the department, whether the participants had undertaken an educational course in death issues, and whether the participants' relatives currently suffered from a serious illness $(\mathrm{P}<0.05)$ (Table 1).

\section{Multivariate analysis of nurses' attitudes towards death}

Multiple linear regression analysis was undertaken, which took the scores of the 5 death attitude dimensions as dependent variables. Variables deemed statistically significant for all dimensions in the single-factor analysis were taken as independent variables. The results revealed that the following factors were statistically significant for some dimensions of the death attitude scale: influence of the nursing staff members' working years, marital status, residence since childhood, whether the participants had rotated departments, whether the participants had undertaken an educational course in death issues, and whether the participants' relatives suffered from serious illness $(\mathrm{P}<0.05)$ (Table 2).

The Pearson correlation coefficient method was used to determine the correlation between the total score of subjective well-being and the death attitude scale dimensions, as well as the influencing factors. The results revealed that the natural acceptance dimension was positively correlated with subjective well-being, while the other four dimensions (i.e., fear of death, avoidance of death issues, tendency towards acceptance, and escape from acceptance) were negatively associated with subjective wellbeing. An association was observed between subjective wellbeing and the following factors: age, initial education level, whether the participants had children, professional title, duties, the number of night shifts, labor form, whether the participants had personally suffered from a serious illness/ acute or chronic disease, and whether the participants' relatives suffered from a serious illness/acute or chronic disease (Table 3).

\section{Multivariate analysis of the subjective well-being of nurses}

Multiple linear regression analysis was undertaken, taking the total score of the subjective well-being scale as the dependent variable. In addition, the following factors were taken as independent variables: the respective scores of fear of death, avoidance of death issues, natural acceptance, tendency towards acceptance, escape from acceptance, age, initial education level, whether the participants had children, professional title, duties, the number of night shifts, labor form, whether the participants had personally suffered from a serious illness/acute or chronic disease, and whether the participants' relatives suffered from a serious illness/acute or chronic disease.

A statistically significant association was observed between the subjective well-being of nurses and the following factors: fear of death, natural acceptance, tendency towards acceptance, escape from acceptance, whether the participants had personally suffered from a 
Table 1 Death attitude scale scores of nurses according to different characteristics $(n=810)$

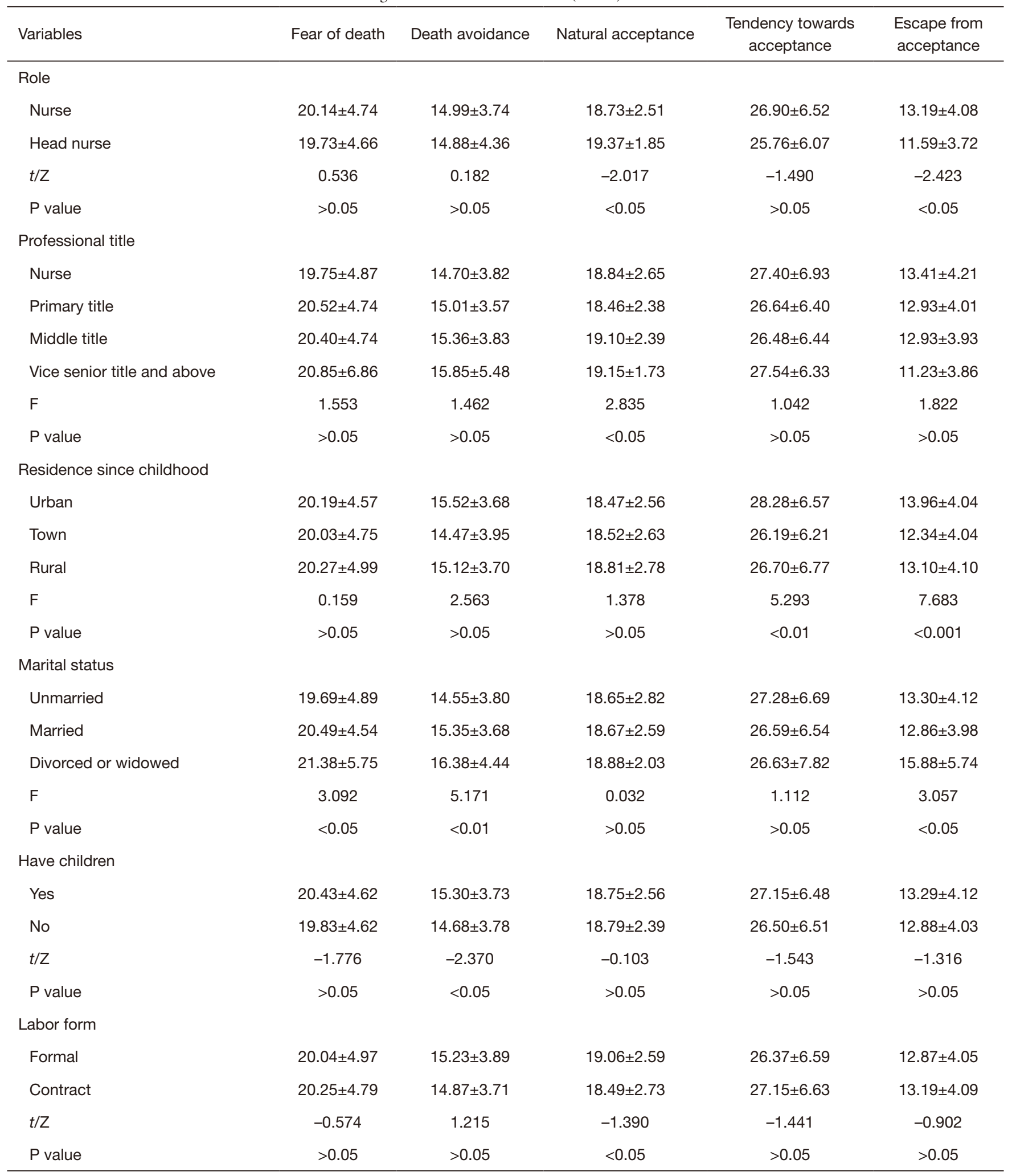

Table 1 (continued) 
Table 1 (continued)

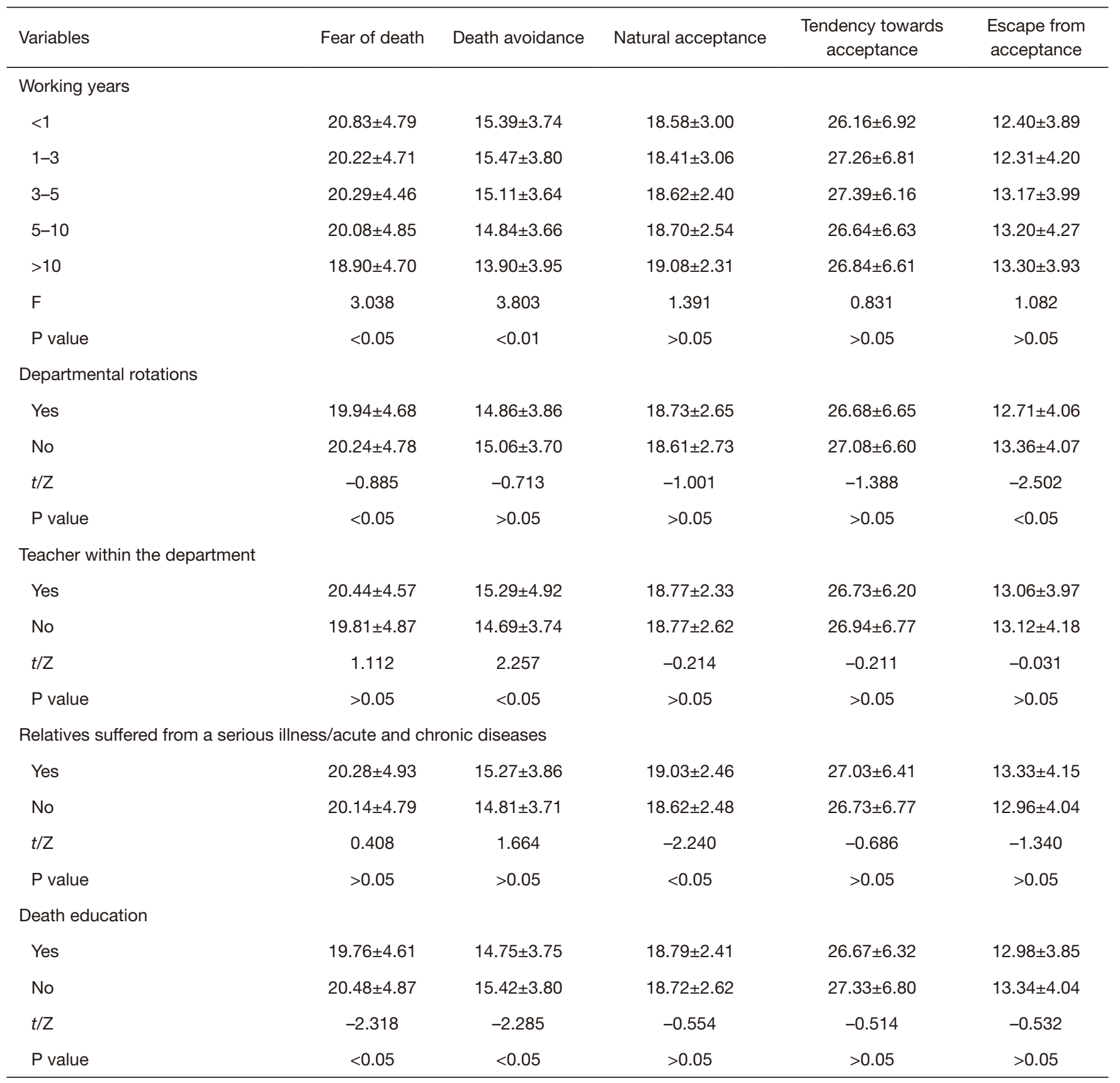

serious illness/acute or chronic disease, the number of night shifts, and initial education level $(\mathrm{P}<0.05)$. With other factors unchanged, subjective well-being was greater when the nurses had never personally suffered from a serious illness/acute or chronic disease, worked less night shifts, had a lower initial education level, and adopted an attitude of natural acceptance towards death. However, subjective well-being was poorer when the nurses adopted attitudes that reflected a fear of death, tendency towards acceptance, and escape from acceptance (Table 4).

\section{Discussion}

An attitude towards death describes the various kinds of 
Table 2 Multiple linear regression analysis of the influencing factors for all dimensions of the death attitude scale among nurses ( $\mathrm{n}=810$ )

\begin{tabular}{|c|c|c|c|c|c|}
\hline Dimension & Independent variables & B & Standard error & $t$ & $P$ value \\
\hline \multirow{2}{*}{ Fear of death } & Working years & 0.330 & 0.124 & 2.661 & 0.008 \\
\hline & Death education & 0.772 & 0.333 & 2.319 & 0.021 \\
\hline \multirow[t]{2}{*}{ Death avoidance } & (Norm) & 13.352 & 0.962 & 13.874 & 0.000 \\
\hline & Working years & 0.275 & 0.134 & 2.061 & 0.040 \\
\hline \multirow[t]{2}{*}{ Natural acceptance } & (Norm) & 20.218 & 0.727 & 27.799 & 0.000 \\
\hline & $\begin{array}{l}\text { Relatives suffered from a serious illness/acute } \\
\text { and chronic diseases }\end{array}$ & -0.397 & 0.182 & -2.181 & 0.030 \\
\hline Escape from acceptance & Departmental rotations & 0.590 & 0.297 & 1.985 & 0.048 \\
\hline
\end{tabular}

moods, psychological dispositions, and evaluations that individuals hold towards death, including their own death, as well as the death of others. This is termed the "moribund stage" (7). The score of natural acceptance was the highest among the nurse participants in the present study, which was consistent with the findings of the research conducted by Park et al. (8). This could be explained by the fact that the nursing staff members had systematically acquired medical knowledge and worked in a clinical capacity for a long period of time, and compared with other groups, had closer and more frequent contact with critically ill patients. The nursing staff members had correctly understood that the end of a person's life is a natural phenomenon. Moreover, situated close to the Guangdong-Hong KongMacao Greater Bay Area, the research institute is based in a coastal region, where local people are wise and find it easier to come to terms with death and death-related issues. The scores of avoidance of death-related issues and fear of death were below the median ( 3 points), indicating that nursing staff members held an attitude of no avoidance and that they experienced little fear, which may be attributed to the specific nature of the nursing profession. The score of tendency towards acceptance was low, which indicated that the nurses in this group disagreed with the viewpoint that people will enjoy afterlife after death. According to previous research, the score of this dimension is mainly related to people's religious beliefs (9). In this research, however, the impact of religious beliefs on the participants' attitudes towards death was unclear. This could be due to the limited representation in the samples in the present study, as only 37 nurses held religious beliefs, accounting for $4.6 \%$, which was a significantly low percentage. However, this finding may be related to the different research tools employed by the researchers. Future studies could use a larger sample size, and different types of religious beliefs could be explored in detail. The score of escape from acceptance was the lowest, which demonstrated that few participants viewed death as a release from the present life. This finding could be due to the fact that our standard of living continues to improve. As such, people tend to experience less hardships and generally enjoy life.

This research found obvious differences with respect to marital status and the avoidance of death-related issues. Nursing staff members who were divorced or widowed scored the highest on the avoidance of death-related issues, followed by married nurses, whereas unmarried nurses scored the lowest. Higher scores for this dimension were associated with a greater tendency towards avoidance of death-related issues. This result highlighted that nursing managers should pay more attention to divorced or widowed nurses, and offer timely psychological counseling to help them develop a more scientific and appropriate view of death, thereby averting any adverse consequences for the quality of nursing provided. Furthermore, the results of this study revealed that the participants' residence since childhood greatly affected tendency towards acceptance 
Table 3 Correlation between subjective well-being and nurses' attitudes towards death, as well as influencing factors ( $\mathrm{n}=810$ )

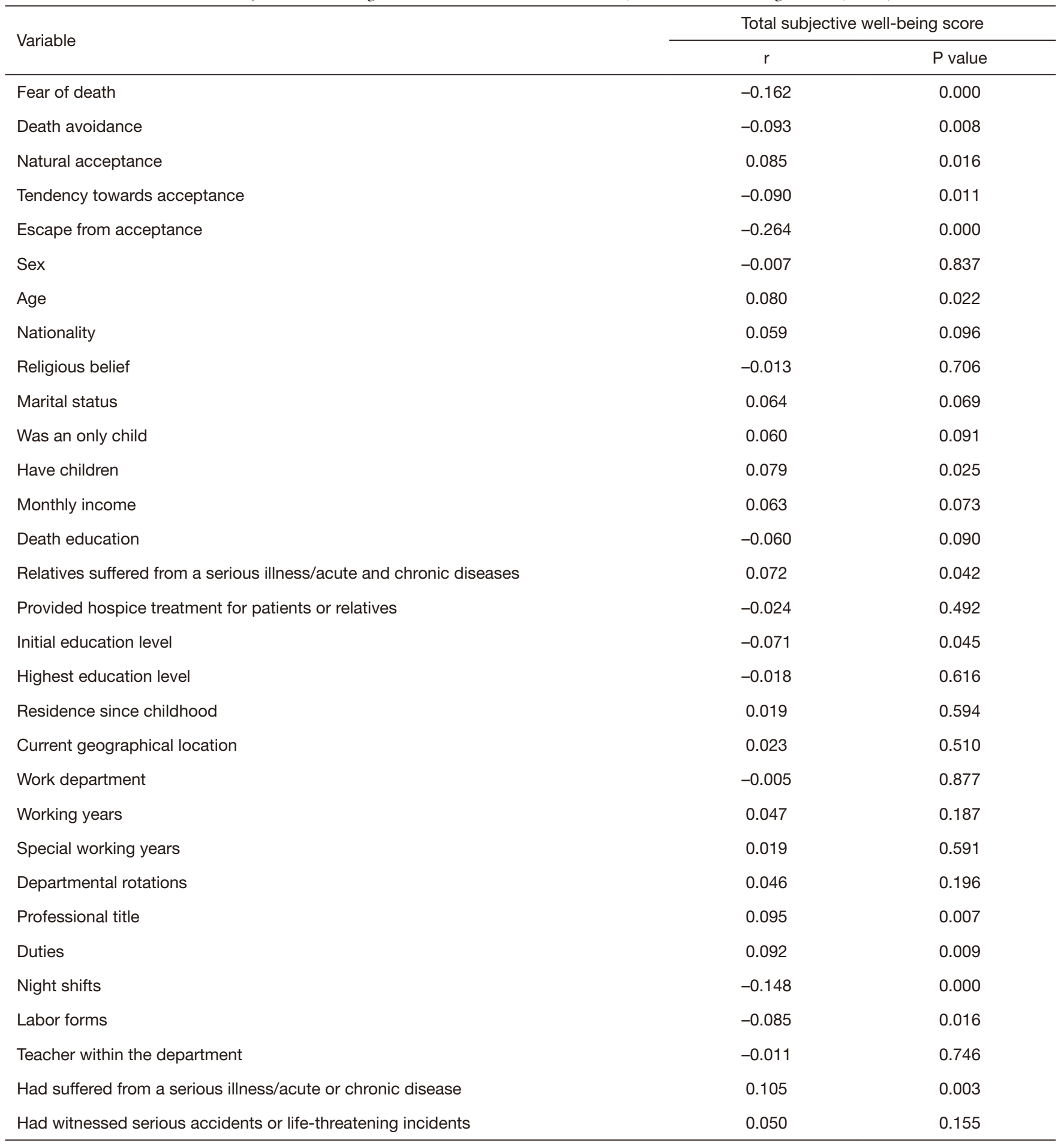


Table 4 Multivariate analysis of the subjective well-being of nurses $(\mathrm{n}=810)$

\begin{tabular}{lccc}
\hline Independent variables & B & Standard error & $t$ \\
\hline (Norm) & 70.940 & 4.687 & 15.135 \\
Fear of death & -0.296 & 0.103 & -2.887 \\
Natural acceptance & 0.332 & 0.133 & 2.501 \\
Tendency towards acceptance & -0.252 & 0.070 & -3.631 \\
Escape from acceptance & -0.841 & 0.112 & -7.538 \\
Suffered from a serious illness/acute or chronic disease & -2.037 & 0.974 & -2.090 \\
Night shifts & -1.562 & 0.409 & -3.013 \\
Initial education level & -0.873 & 0.399 & -2.187 \\
\hline
\end{tabular}

$F=9.860, P<0.001, R^{2}=0.151$, adjusted $R^{2}=0.136$.

and natural acceptance. Nurses who grew up in urban regions were more likely to hold an attitude of acceptance towards death than nurses who grew up in villages, towns, and rural areas, which may be closely related to the growth environment. Nursing staff members who had a longer tenure, who had greater contact with more critically ill patients, and who had acquired a wealth of clinical experience held a less fearful attitude towards death. These nurses confronted death-related issues with a more positive and appropriate attitude, which is consistent with the research findings of Zyga et al. (10). Therefore, during the process of death education, nursing managers should focus on nurses with shorter tenures to help them overcome the fear of death and to confront critically ill patients and death. Nursing staff members who had never undertaken an educational course in death education had markedly higher scores than nurses who had undertaken an educational course in death education. For the fear of death dimension, nurses who had undertaken training in death-related issues were better able to accept death. In their study, Zhao et al. showed that training in death-related issues substantially contributed to fostering a more positive attitude towards death (11). Nurses who had received training in deathrelated issues accounted for only $22.3 \%$, which highlights that it is critical for nurses to receive educational training in death-related issues. The nursing staff members who had sick relatives held a more positive and objective attitude towards death. This could be attributed to their experience of relatives who suffered from a serious illness, which elicited feelings of worry about the prognosis of the disease and led them to contemplate the worst and reflect on death. Such nurses will confront death with calmness, particularly if they have come to realize that death is inevitable. In this research, nursing staff members who had never rotated departments were more likely to avoid acceptance and engage in escapism in terms of their attitude towards death. Among all of the nurses surveyed in this research, those who had rotated departments accounted for $58.9 \%$. This may be due to the standardized training and shift-based system that operated at this hospital. The number and proportion of deceased patients varied between the departments, so differences were also observed in the rate at which nurses encountered death-related issues. Nursing staff members who rotated to special departments, such as the intensive care unit, emergency department, and operating rooms, were more likely to experience patient death than nurses who worked in general wards. The experience of patient death may encourage nurses to develop a more positive attitude towards death and to calmly accept death when it is encountered. Importantly, domestic nurses are bearing huge work tasks and work pressure is greater. Scientific and humanized mode in management is essential adopted by hospitals to improve nurses' active activity. Through strengthening professional knowledge and skills training for nurses to improve the ability of nurses to relieve psychological pressure.

Subjective well-being describes an individual's general evaluation of their living conditions and their level of satisfaction with their life, including feelings associated with the experience positive emotions and the disappearance of negative emotions.. Attitudes towards death are closely related to subjective well-being. In the present study, we carried out a Pearson's correlation analysis, which revealed an association between the scores of subjective well-being among nursing staff and the scores of each death attitude dimension. The natural acceptance dimension was positively 
associated with subjective well-being, which suggested that nursing staff members with greater subjective wellbeing were more likely to accept death. Higher scores of subjective well-being were associated with a more positive attitude towards death and acceptance. The other four dimensions were negatively associated with subjective well-being. Fear and the avoidance of death-related issues caused nurses to experience greater anxiety, which could have an adverse effect on their life satisfaction and positive emotions. Consequently, the subjective well-being of the nursing staff members will decline. These findings are consistent with the research results of $\mathrm{Xu}$ et al. (12), who also believed that clinical nurses who had low sense of fear, who did not actively avoid death-related issues, and who exhibited a high level of acceptance of death were more active in terms of hospice care. Cohen et al. found that attitudes towards death still played an obvious predictable role in subjective well-being, when other variables, such as social support and religious beliefs, were controlled (13). Attitudes towards death affect well-being directly and indirectly. Elderly people in nursing homes are often confronted with the death of a fellow resident, which is an important event in a human's life course. Therefore, it is essential to examine how an individual's attitude towards death affects their opinions about the meaning of life, and ultimately their well-being (14). Studies have found that the attitudes of nurses towards death greatly impact not only their own psychological state but also terminal stage treatment and nursing quality of terminally ill patients $(15,16)$. Moreover, a negative attitude towards death among nurses will reduce life satisfaction and consequently decrease their subjective well-being. Scholars have proposed that the subjective wellbeing of nursing staff members is negatively correlated with the turnover rate. Nurses with lower subjective wellbeing are more likely to experience professional burnout, resulting in a high turnover rate $(17,18)$. The research study (19) explored how training in death-related issues can substantially alleviate an inner sense of fear and escape. For this reason, clinical departments should pay attention to the provision of training in death-related issues and other relevant activities for nursing staff members to help nurses approach death-related issues with a more appropriate and scientific attitude, and to reduce fear in relation to such issues. Furthermore, the provision of educational training can result in better hospice care and encourage staff members to develop a greater sense of meaning in life. Improving the mental health and subjective well-being of nursing staff members can lead to a reduction in the turnover rate of nurses, therefore ensuring greater stability in nursing teams.

\section{Limitations}

This study focused on specific groups of nurses to examine the current situation in respect to attitudes towards death and the influencing factors, as well as the correlation between attitudes towards death and subjective wellbeing. Nurses' attitudes towards death have an impact on their experience of subjective well-being, and subjective well-being can be indirectly promoted by encouraging positive changes in an individual's attitude towards death, therefore improving the quality of the nursing service provided. In addition, this research has some limitations. Future research warrants a larger sample size, and random sampling could be used to carry out a polycentric study to verify the conclusions of the present research. Moreover, qualitative studies can also be conducted to evaluate nurses' understanding of attitudes towards death and their attitudes about subjective well-being, as well as to thoroughly explore the factors that influence nurses' attitudes towards death in order to provide a framework for research on attitudes towards death and trends in training programs. Furthermore, an intervention-based study could be carried out among nurses with different characteristics, and combined with the controllable influencing factors that were identified among the nursing staff in this study as to promote positive changes in attitudes towards death and enhance subjective well-being.

\section{Conclusions}

A close association was found between nurses' attitudes towards death and their subjective well-being. In this grade III, level A hospital, most of the nurses had a natural acceptance of death, but a large number of had a fear of death and tended to avoid this issue. Training in deathrelated issues can help to alleviate the fear of death and encourage nurses to approach death in a more scientific manner, thereby promoting the mental health of staff. Therefore, this study proposes that hospitals provide normalized, scientific, and professional training courses on death-related issues for nursing staff, especially new nurses, while focusing on the cognitive level, emotional level, and technical level. In addition, death education can be incorporated into pre-career training or formal educational settings. In addition to traditional teaching methods, 
educational courses in death-related issues can also be facilitated by conducting case studies, group discussions, experience sharing, or situational simulations, alleviating fear and anxiety in nursing staff when confronted with terminally ill patients, and also by encouraging nurses to develop a scientific attitude towards death and appropriate responses. These measures can result in better subjective well-being and a reduction in the turnover rate of the nursing staff, thereby leading to greater stability in nursing teams, which is fundamental to the provision of higherquality nursing service.

\section{Acknowledgments}

The authors would like to thank all participants in this study.

Funding: None.

\section{Footnote}

Reporting Checklist: The authors have completed the SURGE reporting checklist. Available at https://dx.doi. org/10.21037/apm-21-2943

Data Sharing Statement: Available at https://dx.doi. org/10.21037/apm-21-2943

Conflicts of Interest: All authors have completed the ICMJE uniform disclosure form (available at https://dx.doi. org/10.21037/apm-21-2943). The authors have no conflicts of interest to declare.

Ethical Statement: The authors are accountable for all aspects of the work in ensuring that questions related to the accuracy or integrity of any part of the work are appropriately investigated and resolved. The study was carried out in accordance with the ethical guidelines of the Declaration of Helsinki (as revised in 2013). Ethical approval was received from the Ethic Committee of the Fifth Affiliated Hospital of Sun Yat-sen University (approval No. K221-1). All participants provided written informed consent following an explanation of the procedures involved.

Open Access Statement: This is an Open Access article distributed in accordance with the Creative Commons Attribution-NonCommercial-NoDerivs 4.0 International License (CC BY-NC-ND 4.0), which permits the non- commercial replication and distribution of the article with the strict proviso that no changes or edits are made and the original work is properly cited (including links to both the formal publication through the relevant DOI and the license). See: https://creativecommons.org/licenses/by-nc-nd/4.0/.

\section{References}

1. World Health Organization. (2020). China country assessment report on ageing and health. Geneva: World Health Organization; 2015. Available online: https:// www.who.int/ageing/publications/china-countryassessment/en/

2. Yap SCY, Wortman J, Anusic I, et al. The effect of mood on judgments of subjective well-being: Nine tests of the judgment model. J Pers Soc Psychol 2017;113:939-61.

3. Wang L, Li C, Zhang Q, et al. Clinical nurses' attitudes towards death and caring for dying patients in China. Int J Palliat Nurs 2018;24:33-9.

4. Wong PTP, Reker GT, Gesser G. Death attitude profilerevised: a multidimensional measure of attitude toward death. DC: Washington,1994:121-48.

5. Tang L, Zhang L, Li YX, et al. Validation and reliability of a Chinese version Death Attitude Profile-Revised (DAP-R) for nurses. Journal of Nursing Science 2014;29:64-6.

6. Fazio AF. A concurrent validational study of the NCHS General Well-Being Schedule. Data Evaluation and Methods Research 1977;(73):1-53.

7. Barnett MD, Reed CM, Adams CM. Death Attitudes, Palliative Care Self-efficacy, and Attitudes Toward Care of the Dying Among Hospice Nurses. J Clin Psychol Med Settings 2021;28:295-300.

8. Park KS, Yeom HA. Factors influencing Korean nurses' attitudes towards hospice care. Int Nurs Rev 2014;61:563-9.

9. Braun M, Gordon D, Uziely B. Associations between oncology nurses' attitudes toward death and caring for dying patients. Oncol Nurs Forum 2010;37:E43-9.

10. Zyga S, Malliarou M, Lavdaniti M, et al. Greek renal nurses' attitudes towards death. J Ren Care 2011;37:101-7.

11. Zhao SX, Qiang WM, Zheng XN, et al. Development of death education training content for adult cancer patients: A mixed methods study. J Clin Nurs 2018;27:4400-10.

12. Xu F, Huang K, Wang Y, et al. A Questionnaire Study on the Attitude towards Death of the Nursing Interns in Eight Teaching Hospitals in Jiangsu, China. Biomed Res Int 2019;2019:3107692. 
13. Cohen AB, Hall DE. Existential beliefs, social satisfaction, and well-being among Catholic, Jewish, and Protestant older adults. International Journal for the Psychology of Religion 2009;19:39-54.

14. Krause N. Meaning in life and mortality. J Gerontol B Psychol Sci Soc Sci 2009;64:517-27.

15. Matsui M, Braun K. Nurses' and care workers' attitudes toward death and caring for dying older adults in Japan. Int J Palliat Nurs 2010;16:593-8.

16. Ho TM, Barbero E, Hidalgo C, et al. Spanish nephrology nurses' views and attitudes towards caring for dying patients. J Ren Care 2010;36:2-8.

17. Guo Q, Zheng R. Assessing oncology nurses' attitudes

Cite this article as: Zhang J, Tao H, Mao J, Qi X, Zhou H. Correlation between nurses' attitudes towards death and their subjective well-being. Ann Palliat Med 2021;10(12):12159-12170. doi: 10.21037/apm-21-2943 towards death and the prevalence of burnout: A crosssectional study. Eur J Oncol Nurs 2019;42:69-75.

18. Zhan T, Li H, Ding X. Can social support enhance sense of coherence and perceived professional benefits among Chinese registered nurses? A mediation model. J Nurs Manag 2020;28:488-94.

19. Lomero MDM, Jiménez-Herrera MF, Rasero MJ, et al. Nurses' attitudes and knowledge regarding organ and tissue donation and transplantation in a provincial hospital: A descriptive and multivariate analysis. Nurs Health Sci 2017;19:322-30.

(English Language Editor: R. Scott) 